Article

\title{
Explaining Public Goods Game Contributions with Rational Ability
}

\author{
Hannes Lang ${ }^{1, *(\mathbb{D})}$, Gregory DeAngelo ${ }^{2}$ and Michelle Bongard ${ }^{3}$ \\ 1 School of Life Sciences Weihenstephan, Technische Universität München, Alte Akademie 12, \\ 85354 Freising, Germany \\ 2 Department of Economics, 1601 University Avenue, Morgantown, WV 26506, USA; \\ gregory.deangelo@mail.wvu.edu \\ 3 RAND Corporation, 4570 Fifth Ave \#600, Pittsburgh, PA 15213, USA; Mbongard@rand.org \\ * Correspondence: hanneslang1@gmail.com; Tel.: +49-8161-71-5135
}

Received: 19 March 2018; Accepted: 6 June 2018; Published: 10 June 2018

\begin{abstract}
As the link between psychology and economics has grown, so too has research on the link between personality traits and economic behavior. We build on this previous work, bringing to light the relationship between personality traits and contributions in a one-shot public goods game. We find that contributions to the public good are smaller for rational participants as measured by the Rational-Experiential Inventory-revised 40 (REI-40) item scale. We find no effect on contributions for the measures of the Big Five personality traits or the remaining measures from the REI-40.
\end{abstract}

Keywords: public good; cooperation; psychological traits; REI-40; Big Five

\section{Introduction}

The public goods game has become a classic laboratory environment for studying collective group decisions where participants decide how much to contribute to a common pool. The countervailing effect, however, is that there is an incentive for group members to free-ride on individuals that are contributing positive amounts to the common pool. The Nash Equilibrium for this game is to invest an amount of zero to the public good so long as the marginal per capita return is less than one. An individual in a group in which each participant invests all of their endowment, however, is better off than an individual in a group in which all the participants keep their endowment for themselves. The incentive to free-ride in order to maximize one's own wealth leads to tax fraud, pollution, resource exploitation, and even plays an important role in the climate change issue. This incentive to free-ride, hence, can create huge costs to society both today and in the future. Understanding the behavior in the public goods game is essential when trying to solve these problems. Given the analog to real-world phenomena, research on the public goods game therefore focuses on the factors that lead to, drive, and result in cooperation (see Zelmer [1] for a meta-analysis of the literature).

Explanations for cooperative behavior have been numerous since Andreoni [2] brought the issue to the fore. Further explanations have been posited by Andreoni [3], Gächter et al. [4], and Fosgaard et al. [5]. Andreoni [3] finds that about half of all cooperation is due to some form of kindness and not just confusion about the experiment. Fosgaard et al. [5] find that the way a public good is framed actually affects misperceptions about the incentives of the game and once the misperceptions are removed, the framing difference vanishes. Gächter et al. [4] find that cooperative behavior and reciprocity is dilemma-specific, i.e., depend on the framing of the experiment. Other studies have shown that the rates of contribution to the public good can also be influenced by including options like being excluded from the public good [6,7] or punishment and voting mechanisms [8-10]. Most of 
these studies find that external factors (i.e., the environment and the rules of the game) have an effect on the behavior of the entire group.

In addition to external factors, Fosgaard et al. [5] posit that internal factors have a great part in the observed behavior in a public goods game. To further understand the decision-making process of the group, researchers have explored individual behavior in the public goods game more carefully, including the personality or psychological traits of individual participants. These studies, however, have mostly focused on the Big Five personality traits [11,12], consisting of openness, conscientiousness, extraversion, agreeableness, and neuroticism. The results of these studies have not been consistent. For example, Perugini et al. [13] find that 'agreeableness' of the Big Six measurement (an extension of the Big Five) is a good predictor for cooperative behavior of men in a multi-period public good game. Similarly, Volk et al. [14,15] find that free-riders and conditional cooperators in a public goods game differ in the agreeableness measure of the Big Five, whereas Kurzban and Houser [16] find neuroticism to be statistically significant as a determinant for public goods provisions. Few studies have looked beyond the Big Five as an explanation of individual characteristics correlating with the behavior in a public goods game. Lohse [17], for example, finds a strong and positive relationship between cognitive abilities, as measured by the Cognitive Reflection Test (CRT), and contributions in a one-shot public goods game.

When investigating cooperative behavior beyond the public goods game, the focus is again mostly on the Big Five personality traits [11,12,18]. For example, Lu and Argyle [19] and Ashton et al. [20] find that extraversion is positively correlated with their cooperation-scale, whereas neuroticism has a negative correlation. In accordance with Perugini et al. [13] Lu and Argyle [19] also find agreeableness to be positively correlated with their cooperation-scale. Hirsh and Peterson [21] report that more neurotic individuals were less likely to defect in a prisoner's dilemma game. Ben-Ner et al. [22] find negative significant effects for neuroticism for the giving of females in the dictator game, but in a later paper find correlation between high levels of neuroticism and greater altruism [23].

Studies on the public goods game predict an outcome of zero contributions to the public good, assuming rational and selfish players. The studies mentioned above have shown that participants do cooperate, and they do so for different reasons, or in correlation with some personality traits. While these studies have identified a variety of personality traits correlated with cooperative behavior, we are not aware of any studies directly examining rationality with the behavior in the public goods game. The lack of consensus among these studies and the strong focus on the Big Five personality traits motivate this study of personality traits and their correlation to economic behavior. We add to the ongoing interdisciplinary research on the relationship between economic behavior and personality traits by conducting a battery of psychological and rationality tests, including the Big Five, but also other relevant measurements, that have the potential to explain behavior in the public goods game. Our study, however, is limited in that we cannot determine the motivation for the behavior in the public goods game. While we can identify that participants with a higher rational ability score, we do not know whether their behavior is different from others due to emotional or strategic reasons.

Our research question is:

Which personality or psychological traits determine cooperative behavior in the public goods game?

In the following section, we will present the experimental design of the survey and the public goods game. A section presenting the results follows it. Finally, we will conclude with the conclusion and an outlook on future research.

\section{Experimental Section}

\subsection{Survey}

Students from three different colleges in the Northeast of the United States were invited to take part in our experiment using the universities' respective experimental economics online recruitment 
systems. All participants were required to fill out an online personality traits survey using the website www.surveymonkey.com [24] at least one week prior to being invited to the laboratory. The online survey included the Big Five test [11,12], the REI-40 [25], the Wonderlic score [26], the Holt and Laury Lottery measuring risk aversion [27], and the Mind in the Eyes test [28,29]. The tests were selected either due to their significance in findings of previous research (as mentioned in the review above) or because it was assumed that there could be an intuitive connection between the scores and economic decision-making. Specifically, the Wonderlic score was selected to test for an effect of a participant's problem-solving ability on cooperative behavior, the Mind in the Eyes test was selected to test for an effect of a participant's emotional assessment ability on cooperative behavior, and finally the Holt and Laury lottery was selected to test for an effect of a participant's risk attitude on the behavior in the public goods game.

The Big Five test measures five bipolar factors: openness to experiences (intellect or culture), conscientiousness, extraversion, agreeableness, and neuroticism (Emotional Stability). A number of studies have used the Big Five test to test its factors' correlation with cooperative behavior $[19,20]$, defection behavior [21], and behavior in economic games [22].

The REI-40 is a 40-item self-report test measuring two independent dimensions of human information processing - rational and experiential - that are divided into a total of four subscales: rational ability (ability to think logically and analytically), rational engagement (reliance on and enjoyment of thinking in an analytical manner), experiential ability (ability to trust one's intuition and feelings), and experiential engagement (reliance on and enjoyment of using intuition in decision making) [25].

The Wonderlic test [26] is an intelligence test that is used to assert the learning and problem-solving ability of participants.

The Holt and Laury Lottery comprises 10 consecutive choices between paired lotteries in which the transition from a less risky lottery A to the more risky lottery B is incentivized by an increasing risk premium. A participant's risk attitude can be measured by observing when the participant switches between the lotteries. The Holt and Laury lottery has become a standard method for eliciting risk attitudes of participants in economic experiments [30].

The Mind in the Eyes test, a measure of Theory of Mind, has been more commonly used to examine the differences in the ability to read another person's emotional state in adults with autism spectrum conditions [28,31-33]. The test examines differences in a participant's emotional assessment ability, i.e., the ability of a participant to put herself into the mind of another person and make sense of that person's behavior.

Some of the personality traits can be expected to have little correlation with the behavior in a public goods game. For example, in the Big Five personality traits, openness to experience or conscientiousness are not likely to correlate with cooperative behavior as they refer to more risk-related issues. Not surprisingly, these measures were also not statistically significant in our analysis. In the REI-40, however, rational ability and rational engagement could be expected to show some influence. Rational ability refers to the individual's tendency to think analytically and make logical connections, whereas experiential ability refers to being affective (i.e., doing what feels good) and reliant on past experiences. A more rational individual relies less on the past experiences for their decision and might think more thoroughly about the consequences of different strategies in a particular situation. They could conclude that her/his own actions have no influence on others' contributions, since it is a one-shot game and there are no repercussions for un-cooperative behavior in this instance. Hence, we hypothesize that individuals who score higher on the rational ability measure will also invest less in the public good.

\subsection{Public Goods Game}

All participants who successfully finished the survey were then invited to participate in the laboratory experiment. At the beginning of each session participants were asked for demographic 
data: age, gender, major, and college-years. Each participant then played the following games in random order: the dictator game, the ultimatum game, the minimum effort game, and the prisoner's dilemma game. After finishing these games, all participants played a one-shot public goods game in which each participant could contribute to a public good and each contribution resulted in a payoff to all participants in the group, including one's self. The participants had to choose how much of a $\$ 1$ endowment they would like to invest in the public good. How much to invest could be chosen in 1 cent increments. In addition to the amount that each participant kept for themselves, she/he received a payout in the amount of half of the amount invested by the entire group. In a game with $n$ participants the pay-off for the $i$-th person was:

$$
p_{i}=\left(1-c_{i}\right)+0.5 \sum_{j=1}^{n} c_{j}
$$

where $c_{i}$ is the individual's investment in the public good and $c_{j}$ is the investment made by each $j$ th group member. The participants were informed that investments are made anonymously and cannot be identified.

\section{Results}

Out of the 140 participants, 55 were female and 85 were male. Group sizes varied from 8 to 16 and the average contribution was around 50 cents, which led to an average payout of $\$ 3.41$ with a minimum of $\$ 1.63$ and a maximum of $\$ 5.1$.

Since the group sizes varied, while the marginal per capita return (MPCR) stayed constant, the gains from cooperation also change. This could influence the contribution decision of participants in different groups. Research by Isaac et al. [34] found a difference in efficiency due to group size at a lower MPCR of 0.30 , while at a MPCR of 0.70 no statistically significant difference was found. We find no significant differences between average contributions of participants in different groups. There are two explanations for this: (i) the MPCR in this experiment is 0.5 and hence too high to allow group size to be an important factor; (ii) the effect of group size might not be an important factor in a one-shot game. Contributions in the first round in the study by Isaac et al. [34] were between $40 \%$ and $50 \%$ of the initial endowment for almost all group sizes (except for the smallest group size of 4). Similarly, we checked for heterogeneous effects of group size and other important variables (specifically gender and rational ability) and found no statistically significant result.

The important personality variable for the analysis of the behavior in the public goods game turns out to be rational ability as measured by the REI-40 [25], where rational ability refers to having a high level of ability to think logically and analytically. Our sample value of an average 3.30 out of 5 for rational ability is lower than the value of 4.0 out of 5 found by Sladek et al. [35], but close to the value of 3.39 for American College Students found by Calder et al. [36].

Table 1 gives a summary of statistics of the important variables. 
Table 1. Summary statistics.

\begin{tabular}{lcc}
\hline Variable & Median/Mean & S.D. \\
\hline Age & $22 / 21.5$ & 2.07 \\
Group size & $10 / 11.4$ & 2.66 \\
Public Good Outcome & $3.4 / 3.41$ & 0.827 \\
Public Good Contribution & & \\
- for all participants $(N=140)$ & $0.5 / 0.502$ & 0.392 \\
- for all males $(N=85)$ & $0.5 / 0.517$ & 0.429 \\
- for all females $(N=55)$ & $0.5 / 0.478$ & 0.329 \\
- for group size $=8(N=32)$ & $0.5 / 0.495$ & 0.400 \\
- for group size $=10(N=40)$ & $0.5 / 0.498$ & 0.388 \\
- for group size $=12(N=24)$ & $0.64 / 0.566$ & 0.394 \\
- for group size $=14(N=28)$ & $0.45 / 0.454$ & 0.395 \\
- for group size $=16(N=16)$ & $0.5 / 0.513$ & 0.416 \\
Rationality & & \\
- for all participants $(N=140)$ & $3.3 / 3.29$ & 0.712 \\
- for all males $(N=85)$ & $3.3 / 3.198$ & 0.755 \\
- for all females $(N=55)$ & $3.5 / 3.42$ & 0.623 \\
\hline
\end{tabular}

The average contribution of females and males was close with $\$ 0.478$ and $\$ 0.517$, respectively, and its magnitude was in line with previous experiments $[3,37,38]$. Similarly, the average value of public good contribution for different group sizes was between 0.45 and 0.64 , with no trend for either increasing size numbers. We will now discuss the analysis of the personality traits.

\section{Personality Traits}

Rational choice theory suggests that the rational actor tries to maximize personal payout by investing the minimum amount possible, in this case zero, in the public good. In the ex-ante survey, participant's rational ability was tested as a factor in the REI-40 [25], and we found that participants whose score showed higher rational ability also contributed significantly less to the public good. Since the measure for rational ability can take on many values, we divided participants in five groups to facilitate the interpretation of the values. Since most participants achieved a score between 3 and 4 and very few participants achieve a score lower than 2 , we adjusted the interval of the rational ability score to get a more even distribution of observations between the groups. Table 2 shows the relevant statistics.

Table 2. Investment in public good by participants with different rational ability scores.

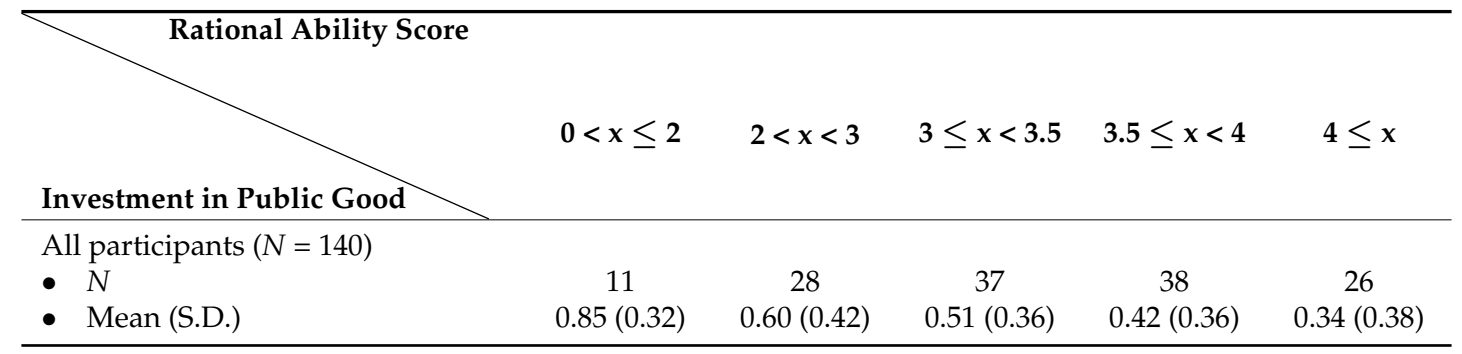

The table shows a decrease in investment in the public good from 0.85 for very low scores to less than half the initial endowment for scores higher than 3.5. Further tests were run for the variety of personality and economic traits we had collected in the online survey and no other variable showed a statistical significance similar to the rational ability measure.

In the next step, a regression analysis was used to see if the statistical significance holds when controlling for other sources of variation. Table 3 shows the results of the OLS regression analysis with robust standard errors. Since our analysis tests which personality traits determine cooperative behavior 
in the public goods game (i.e., we are testing multiple hypotheses), we are reporting Bonferroni and Sidak corrected p-values [39].

Model 1 is the simplest model, only including rational ability, risk aversion, and age. In Model 2 , we add gender and group size, and in model 3 we control for college-related variables, such as the number of years the participant has been in college, the college the participant attends and their major. In Model 4, we test for the Big Five personality traits, while removing the control variables from model 3, as they showed no statistical significance. Finally, in Model 5, we test for the Wonderlic score, the Mind in the Eyes score and the remaining measure from the REI-40. Besides age, none of the control variables showed statistical significance in any of the models.

Table 3. Regression results: PG contribution.

\begin{tabular}{|c|c|c|c|c|c|}
\hline PG Contribution & Model 1 & Model 2 & Model 3 & Model 4 & Model 5 \\
\hline Rational Ability & $\begin{array}{l}-0.155^{* *} \\
(0.047)\end{array}$ & $\begin{array}{l}-0.153^{* *} \\
(0.047)\end{array}$ & $\begin{array}{l}-0.150 * \\
(0.048)\end{array}$ & $\begin{array}{c}-0.176 \\
* *(0.047)\end{array}$ & $\begin{array}{c}-0.219^{*} \\
(0.067)\end{array}$ \\
\hline Risk Aversion & $\begin{array}{l}-0.001 \\
(0.075)\end{array}$ & $\begin{array}{c}0.005 \\
(0.076)\end{array}$ & $\begin{array}{c}0.006 \\
(0.078)\end{array}$ & $\begin{array}{c}0.047 \\
(0.085)\end{array}$ & $\begin{array}{l}-0.004 \\
(0.078)\end{array}$ \\
\hline Age & $\begin{array}{l}0.037^{* *} \\
(0.012)\end{array}$ & $\begin{array}{l}0.043 * * \\
(0.013)\end{array}$ & $\begin{array}{c}0.034 \\
(0.017)\end{array}$ & $\begin{array}{l}0.038^{*} \\
(0.013)\end{array}$ & $\begin{array}{l}0.048^{* *} \\
(0.014)\end{array}$ \\
\hline Male & & $\begin{array}{c}0.015 \\
(0.061)\end{array}$ & $\begin{array}{c}0.038 \\
(0.072)\end{array}$ & $\begin{array}{c}0.022 \\
(0.060)\end{array}$ & $\begin{array}{c}0.016 \\
(0.069)\end{array}$ \\
\hline Group Size & & $\begin{array}{l}-0.014 \\
(0.012)\end{array}$ & $\begin{array}{l}-0.012 \\
(0.014)\end{array}$ & $\begin{array}{l}-0.009 \\
(0.013)\end{array}$ & $\begin{array}{l}-0.014 \\
(0.012)\end{array}$ \\
\hline Big 5-Extraversion & & & & $\begin{array}{c}0.016 \\
(0.050)\end{array}$ & \\
\hline Big 5-Agreeableness & & & & $\begin{array}{c}0.079 \\
(0.059)\end{array}$ & \\
\hline Big 5-Consciousness & & & & $\begin{array}{l}-0.126 \\
(0.065)\end{array}$ & \\
\hline Big 5-Neuroticism & & & & $\begin{array}{c}0.067 \\
(0.055)\end{array}$ & \\
\hline Big 5-Openness & & & & $\begin{array}{l}-0.060 \\
(0.057)\end{array}$ & \\
\hline Rational Engagement & & & & & $\begin{array}{c}0.089 \\
(0.058)\end{array}$ \\
\hline Experiential Ability & & & & & $\begin{array}{c}0.014 \\
(0.076)\end{array}$ \\
\hline Experiential Engagement & & & & & $\begin{array}{l}-0.031 \\
(0.079)\end{array}$ \\
\hline Wonderlic Score & & & & & $\begin{array}{l}-0.006 \\
(0.007)\end{array}$ \\
\hline Mind in the Eyes Score & & & & & $\begin{array}{l}-0.007 \\
(0.010)\end{array}$ \\
\hline Constant & $\begin{array}{c}0.206 \\
(0.348)\end{array}$ & $\begin{array}{c}0.188 \\
(0.352)\end{array}$ & $\begin{array}{c}0.132 \\
(0.408)\end{array}$ & $\begin{array}{c}0.349 \\
(0.390)\end{array}$ & $\begin{array}{c}0.500 \\
(0.507)\end{array}$ \\
\hline Control Variables & No & No & $\begin{array}{l}\text { College, Major, Years } \\
\text { in College }\end{array}$ & No & No \\
\hline$R^{2}$ & 0.138 & 0.145 & 0.160 & 0.196 & 0.172 \\
\hline Adjusted $R^{2}$ & 0.119 & 0.114 & 0.088 & 0.133 & 0.108 \\
\hline$F$ & $11.46^{* * *}$ & $7.712^{* * *}$ & $4.412 * * *$ & $6.050 * * *$ & $4.010 * * *$ \\
\hline
\end{tabular}

The coefficient for rational ability is statistically significant and has negative values between -0.15 and -0.22 for all five models. As predicted by standard economic theory, we find that the higher the score of a participant on the rational ability scale, the less likely that participant is to invest in the public good. Investing little into the public good is predicted by the Nash equilibrium solution concept, which assumes rational players. It is, therefore, not surprising that participants scoring higher on the rational ability measure are also more likely to play the Nash equilibrium solution concept. 
Adding the variable male and group size has almost no effect on the other variables and actually decreases the value for the F-test and the adjusted R-squared. Neither male nor group size is statistically significant. Table 1 shows that average contribution differs very little between different group sizes and gender, and hence the lack of statistical significance is not surprising. ${ }^{1}$

Controlling for the level of risk aversion, we did not find statistical significance in our results. In this case, the reason might be that investing more rather than less is not perceived as a risk, because the participant's choice does not affect the probability of different outcomes. The coefficient for age shows up as being statistically significant in all models except model 3 and is positive for all five models. We do not allow ourselves a reliable interpretation, since the coefficient is not statistically significant in all models.

In model 4, we tested for the correlation of the measures of the Big Five personality factors; however, none of the coefficients showed up as being statistically significant. In model 5, we tested for the Wonderlic score, the Mind in the Eyes score and for the remaining personality traits from the REI-40 test-rational engagement, experiential ability, and experiential engagement. Again, none of the coefficients were found to be statistically significant. In accordance with earlier studies on personality traits and economic games, we continue to find that, as much as the tests we apply can measure very specific personality traits, these traits only correlate with behavior in very specific environments.

The findings of previous studies explaining PG contributions with personality traits, specifically measures of the Big Five personality traits, could not be confirmed. Rather, we find that when we place personality measures and measures of rationality into the empirical estimation, we find that the rationality measures are statistically significantly associated with PG contributions.

\section{Conclusions}

The results in this paper show that rational ability as measured by the REI-40 is a good predictor for behavior in the public goods game. As predicted by rational choice theory, a more rational individual contributes less to the public goods game. Rational ability refers to the individual's tendency to think analytically and make logical connections, whereas the other thinking style-experiential-refers to being affective (i.e., doing what feels good) and reliant on past experiences [40]. Most interactions in the real world are not 'one-shot' and not as isolated as a laboratory experiment. This also means that un-cooperative behavior can have negative repercussions in an individual's future. From these experiences, many people learn intuitively to act cooperatively, especially if they have an experiential thinking style. An individual with a tendency for a rational thinking style, in contrast, relies less on past experiences for their decision-making.

In addition to rationality measures, we included measures for personality and psychological traits, a test for intelligence, and an empathy measure. In contrast to previous results that find measures of the Big Five personality traits to be significant, we find null results for these variables. The null result on the non-rationality covariates provides some confidence that rationality is an important driver of PG contributions. However, it is possible that heterogeneous effects between rationality and other covariates could exist, but the current study cannot examine such effects.

With this study, we contribute to the ongoing interdisciplinary research on the relationship between economic behavior and personality traits. We confirm the intuitive finding that rational individuals contribute less to the public good. We also find that none of the other tested personality traits-the Big Five personality traits, the remaining measures from the REI-40, the Wonderlic score and the Mind in the Eyes score-show a significant correlation with giving in the public goods game of our experiment.

1 In unreported results, we include a series of interaction variables between group size, gender and other control variables. None of these interaction effects were statistically significant and, hence, we do not report these results here. 
Author Contributions: All authors conceived, designed and performed the experiments; H.L. analyzed the data; G.D. and M.B. contributed to the interpretation and discussion of the data analysis and results; H.L. wrote the paper.

Acknowledgments: The study was funded by a grant from the Koch Foundation.

Conflicts of Interest: The authors declare no conflict of interest. The sponsors had no role in the design of the study; in the collection, analyses, or interpretation of data; in the writing of the manuscript, and in the decision to publish the results.

\section{References}

1. Zelmer, J. Linear Public Goods Experiments: A Meta-Analysis. Exp. Econ. 2003, 6, 299-310. [CrossRef]

2. Andreoni, J. Why free ride?: Strategies and learning in public goods experiments. J. Public Econ. 1988, 37, 291-304. [CrossRef]

3. Andreoni, J. Cooperation in public-goods experiments: Kindness or confusion? Am. Econ. Rev. 1995, 891-904.

4. Gächter, S.; Kölle, F.; Quercia, S. Reciprocity and the tragedies of maintaining and providing the commons. Nat. Hum. Behav. 2017, 1, 650-656. [CrossRef] [PubMed]

5. Fosgaard, T.R.; Hansen, L.G.; Wengström, E. Framing and Misperception in Public Good Experiments. Scand. J. Econ. 2017, 119, 435-456. [CrossRef]

6. Semmann, D.; Krambeck, H.-J.; Milinski, M. Volunteering leads to rock-paper-scissors dynamics in a public goods game. Nature 2003, 425, 390-393. [CrossRef] [PubMed]

7. Romaniuc, R.; Dubois, D.; DeAngelo, G.; McCannon, B. Intergroup Solidarity and Local Public Goods Provision: An Experiment; Working Papers; Universitiy of Montpellier: Montpellier, France, 2018.

8. Cinyabuguma, M.; Page, T.; Putterman, L. Cooperation under the threat of expulsion in a public goods experiment. J. Public Econ. 2005, 89, 1421-1435. [CrossRef]

9. Fehr, E.; Gächter, S. Cooperation and Punishment in Public Goods Experiments. Am. Econ. Rev. 2000, 90, 980-994. [CrossRef]

10. Czap, H.J.; Czap, N.V.; Bonakdarian, E. Walk the Talk? The Effect of Voting and Excludability in Public Goods Experiments. Available online: https:/ / www.hindawi.com/journals/ecri/2010/768546/abs/ (accessed on 8 March 2018).

11. John, O.P.; Donahue, E.M.; Kentle, R.L. The Big Five Inventory_Versions 4a and 54; University of California, Berkeley, Institute of Personality and Social Research: Berkeley, CA, USA, 1991.

12. John, O.P.; Naumann, L.P.; Soto, C.J. Paradigm shift to the integrative big five trait taxonomy. In Handbook of Personality: Theory and Research; The Guilford Press: New York, NY, USA; London, UK, 2008; pp. 114-158, ISBN 978-1-59385-836-0.

13. Perugini, M.; Tan, J.H.; Zizzo, D.J. Which is the more predictable gender? Public good contribution and personality. Econ. Issues 2010, 15, 83-110. [CrossRef]

14. Volk, S.; Thöni, C.; Ruigrok, W. Temporal stability and psychological foundations of cooperation preferences. J. Econ. Behav. Organ. 2012, 81, 664-676. [CrossRef]

15. Volk, S.; Thöni, C.; Ruigrok, W. Personality, personal values and cooperation preferences in public goods games: A longitudinal study. Personal. Individ. Differ. 2011, 50, 810-815. [CrossRef]

16. Kurzban, R.; Houser, D. Individual differences in cooperation in a circular public goods game. Eur. J. Personal. 2001, 15, S37-S52. [CrossRef]

17. Lohse, J. Smart or selfish-When smart guys finish nice. J. Behav. Exp. Econ. 2016, 64, 28-40. [CrossRef]

18. Benet-Martinez, V.; John, O.P. Los Cinco Grandes across cultures and ethnic groups: Multitrait-multimethod analyses of the Big Five in Spanish and English. J. Pers. Soc. Psychol. 1998, 75, 729. [CrossRef] [PubMed]

19. Lu, L.; Argyle, M. Happiness and cooperation. Personal. Individ. Differ. 1991, 12, 1019-1030. [CrossRef]

20. Ashton, M.C.; Paunonen, S.V.; Helmes, E.; Jackson, D.N. Kin altruism, reciprocal altruism, and the Big Five personality factors. Evol. Hum. Behav. 1998, 19, 243-255. [CrossRef]

21. Hirsh, J.B.; Peterson, J.B. Extraversion, neuroticism, and the prisoner's dilemma. Personal. Individ. Differ. 2009, 46, 254-256. [CrossRef]

22. Ben-Ner, A.; Kong, F.; Putterman, L. Share and share alike? Gender-pairing, personality, and cognitive ability as determinants of giving. J. Econ. Psychol. 2004, 25, 581-589. [CrossRef] 
23. Ben-Ner, A.; Kramer, A. Personality and altruism in the dictator game: Relationship to giving to kin, collaborators, competitors, and neutrals. Personal. Individ. Differ. 2011, 51, 216-221. [CrossRef]

24. SurveyMonkey. Available online: www.surveymonkey.com (accessed on 17 August 2013).

25. Pacini, R.; Epstein, S. The relation of rational and experiential information processing styles to personality, basic beliefs, and the ratio-bias phenomenon. J. Personal. Soc. Psychol. 1999, 76, 972-987. [CrossRef]

26. Wonderlic, E.F. Wonderlic Personnel Test and Scholastic Level Exam: User's Manual; Wonderlic and Associates: Northfield, IL, USA, 1992.

27. Holt, C.A.; Laury, S.K. Risk aversion and incentive effects. Am. Econ. Rev. 2002, 92, 1644-1655. [CrossRef]

28. Baron-Cohen, S.; Wheelwright, S.; Hill, J.; Raste, Y.; Plumb, I. The "Reading the Mind in the Eyes" Test revised version: A study with normal adults, and adults with Asperger syndrome or high-functioning autism. J. Child Psychol. Psychiatry 2001, 42, 241-251. [CrossRef] [PubMed]

29. Baron-Cohen, S.; Jolliffe, T.; Mortimore, C.; Robertson, M. Another advanced test of theory of mind: Evidence from very high functioning adults with autism or Asperger syndrome. J. Child Psychol. Psychiatry 1997, 38, 813-822. [CrossRef] [PubMed]

30. Hirschauer, N.; Musshoff, O.; Maart-Noelck, S.C.; Gruener, S. Eliciting risk attitudes-How to avoid mean and variance bias in Holt-and-Laury lotteries. Appl. Econ. Lett. 2014, 21, 35-38. [CrossRef]

31. Craig, J.S.; Hatton, C.; Craig, F.B.; Bentall, R.P. Persecutory beliefs, attributions and theory of mind: Comparison of patients with paranoid delusions, Asperger's syndrome and healthy controls. Schizophr. Res. 2004, 69, 29-33. [CrossRef]

32. Golan, O.; Baron-Cohen, S.; Hill, J. The Cambridge Mindreading (CAM) Face-Voice Battery: Testing Complex Emotion Recognition in Adults with and without Asperger Syndrome. J. Autism Dev. Disord. 2006, 36, 169-183. [CrossRef] [PubMed]

33. Murphy, D. Theory of mind in Asperger's syndrome, schizophrenia and personality disordered forensic patients. Cognit. Neuropsychiatry 2006, 11, 99-111. [CrossRef] [PubMed]

34. Isaac, R.M.; Walker, J.M.; Williams, A.W. Group size and the voluntary provision of public goods: Experimental evidence utilizing large groups. J. Public Econ. 1994, 54, 1-36. [CrossRef]

35. Sladek, R.M.; Bond, M.J.; Phillips, P.A. Age and gender differences in preferences for rational and experiential thinking. Personal. Individ. Differ. 2010, 49, 907-911. [CrossRef]

36. Calder, L.A.; Forster, A.J.; Stiell, I.G.; Carr, L.K.; Brehaut, J.C.; Perry, J.J.; Vaillancourt, C.; Croskerry, P. Experiential and rational decision making: A survey to determine how emergency physicians make clinical decisions. Emerg. Med. J. 2011. [CrossRef] [PubMed]

37. Fujimoto, H.; Park, E.-S. Framing effects and gender differences in voluntary public goods provision experiments. J. Socio-Econ. 2010, 39, 455-457. [CrossRef]

38. Park, E.-S. Warm-glow versus cold-prickle: A further experimental study of framing effects on free-riding. J. Econ. Behav. Organ. 2000, 43, 405-421. [CrossRef]

39. Abdi, H. The Bonferonni and Šidák Corrections for Multiple Comparisons. In Encyclopedia of Measurement and Statistics; Salkind, N., Ed.; Sage: Thousand Oaks, CA, USA, 2007; p. 9.

40. Epstein, S.; Pacini, R.; Denes-Raj, V.; Heier, H. Individual differences in intuitive-experiential and analytical-rational thinking styles. J. Personal. Soc. Psychol. 1996, 71, 390-405. [CrossRef]

(C) 2018 by the authors. Licensee MDPI, Basel, Switzerland. This article is an open access article distributed under the terms and conditions of the Creative Commons Attribution (CC BY) license (http:/ / creativecommons.org/licenses/by/4.0/). 